\title{
Mouse renal 4T1 cell engraftment as a model to study the influence of hypoxia in breast cancer progression ${ }^{1}$
}

\author{
Heriton Marcelo Ribeiro Antonio', Larissa Raquel Mouro MandaranoI, Alan Augusto Coelho" ${ }^{\mathrm{II}}$, Marcelo Guimarães Tiezzi ${ }^{\mathrm{III}}$, \\ Jurandyr Moreira de Andrade ${ }^{\mathrm{IV}}$, Daniel Guimarães Tiezzi \\ IFellow PhD degree, Postgraduate Program in Gynecology and Obstetrics, Breast Disease Unit, Department of Gynecology and Obstetrics, Ribeirao \\ Preto School of Medicine, USP, Sao Paulo, Brazil. Intellectual and scientific content of the study, technical procedures, critical revision.

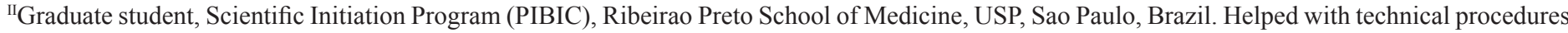 \\ and preparation of histological sections.

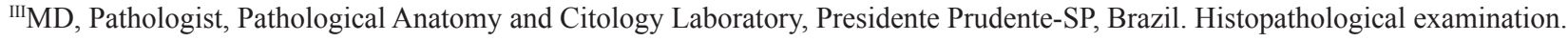

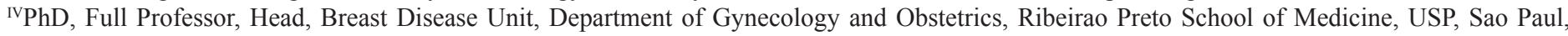 \\ Brazil. Conception and design of the study, critical revision. \\ ${ }^{\mathrm{v}} \mathrm{PhD}$, Assistant Professor, Breast Disease Unit, Department of Gynecology and Obstetrics, Ribeirao Preto School of Medicine, USP, Sao Paulo, Brazil. \\ Main author. Design and supervised all phases of the study.
}

\begin{abstract}
PURPOSE: To develop a mouse model to study the influence of hypoxia in breast cancer progression and metastasis.

METHODS: The 4T1 cell line was used to engraft the kidneys of female BALB/c mice. Placing an aneurysm clip on the kidney hilum, hypoxia can be directed to tumor site. Histological evaluation was used to analyze the morphological changes induced by ischemia in kidney cortex, and to verify the metastatic potential.

RESULTS: 4T1 cells can be engrafted into the renal cortex and the renal ischemia caused by using a clip to clamp the renal hilum induces hypoxia at the tumor site. This procedure maintains the ability of 4T1 cells to metastasize. In fact, our preliminary results showed that tumor hypoxia precipitates the metastatic dissemination of tumor cells. After 14 days of engraftment, lung metastases were observed only in mice that were subjected to tumor hypoxia.
\end{abstract}

CONCLUSION: This model can help us to understand how low oxygen tension mediates hypoxia-induced proteomic and genomic changes in breast cancer.

Key words: Models, Animal. Breast Neoplasms. Anoxia. Kidney. Mice. 


\section{Introduction}

Cancer progression associated with abnormal vasculature and attenuated blood flow leads to tumor hypoxia. Low levels of oxygen within cells are characteristic of many solid malignant tumors ${ }^{1}$. This phenomenon has been described as an important trigger of tumor invasion, growth, and development of metastasis ${ }^{2,3}$. Clinical evidence has demonstrated that hypoxia is associated with a poor prognosis in several cancer types, including breast cancer $^{2,4-6}$. Despite the importance of this association between hypoxia and more aggressive cancer phenotypes, experimental models to study the influence of hypoxia in cancer development and progression have been limited to in vitro models and in vivo models based on mice being subject to a systemic hypoxic state or drug-induced hypoxia. These models have provided inconclusive and controversial data $^{7,8}$.

While in vitro models and drug-induced hypoxia in vivo rely on the observation that tumor hypoxia works as an adverse prognostic factor ${ }^{8-10}$, some in vivo models have reported no influence on or the repression of tumor progression ${ }^{7,11}$. It has been hypothesized that a systemic hypoxic state is not able to reproduce the clinical significance of tumor hypoxia and that the subcutaneous xenograft model may significantly overestimate the degree of hypoxia ${ }^{12}$. Thus, the development of an in vivo model is proposed, whereby a controlled hypoxic state is directed specifically to the primary tumor site. It is hypothesized that this model more accurately reflects the manner in which low oxygen tension in tumor cells can modulate tumor phenotypes, cancer invasion and dissemination. The objective of this study was to develop a more representative and accurate in vivo model of tumor hypoxia in mice.

\section{Methods}

The study was approved by the CETEA-USP Animal Ethics Committee (USP, Ribeirao Preto-SP, Brazil). BALB/c mice were housed in groups of 4 in $32 \mathrm{~cm} \mathrm{x} 20 \mathrm{~cm}$ x $21 \mathrm{~cm}$ polycarbonate microisolator cages (Alesco ${ }^{\circledR}$ - ALE.MIL.01, Brazil). Mice were maintained at room temperature $\left(22^{\circ} \mathrm{C}\right)$ and relative humidity at $60 \%$ with cages changed twice a week. Mice were fed with Nuvilab CR-1 (Nuvital, Brazil). Food and tap water were available ad libitum.

\section{Cell culture}

The 4T1 cell line was cultured in RPMI medium with $5 \%$ FBS until achieving $80 \%$ confluence in a $75 \mathrm{~cm}^{2}$ culture flask. After trypsinization, cells were harvested, and the number of live cells was estimated using a Neubauer chamber and the trypan blue exclusion assay.

\section{Establishment of a breast cancer allograft into the kidney}

Eight mice, at 5-6 weeks of age, were used for the renal allograft transplantation of $4 \mathrm{~T} 1$ cells. A total of $5 \times 10^{4}$ or $10^{5} 4 \mathrm{~T} 1$ live cells suspended in $30 \mu \mathrm{l}$ of RPMI medium were injected into the left kidney of the recipient mouse. After anesthetic induction with intraperitoneal (i.p.) ketamine $(60 \mathrm{mg} / \mathrm{kg})$ and xylazine $(8$ $\mathrm{mg} / \mathrm{kg}$ ), a dorsal para-median incision was made, and the left kidney was identified. Using a $29 \mathrm{G}$ needle, cells were injected into the kidney parenchyma. The organ was replaced into the abdominal cavity, and an interrupted suture was performed to close the incision. Morphine Sulfate $\left(\right.$ Dimorf $^{\mathbb{R}}$ ) $0.98 \mathrm{mg} / \mathrm{kg}$ was injected subcutaneously for postoperative analgesia. Mice were monitored by palpation every two days. After 14 days, the mice were sacrificed, and the kidneys were removed, fixed in $10 \%$ formaldehyde and processed in paraffin blocks.

\section{Induction of renal ischemia}

A total of eight BALBc mice were anesthetized using the same protocol described above and an abdominal para-median longitudinal incision was made. Using a surgical microscope DFV (DF Vasconcelos, Brazil), the left kidney and its hilum were identified, and a suture knot $(n=)$ or an aneurysm clip $(n=4)$ was placed in order to completely obstruct renal blood flow. The renal hilum was clamped to induce a state of renal ischemia. The clip was applied for 40 minutes, at which point renal ischemia was detected, and then removed. Renal re-perfusion was evident after removing the clip (Figure 1, A-C). The abdominal wall was closed with an interrupted suture. After 24 hours, the mice were sacrificed, and both kidneys were surgically removed for histological assessment. 


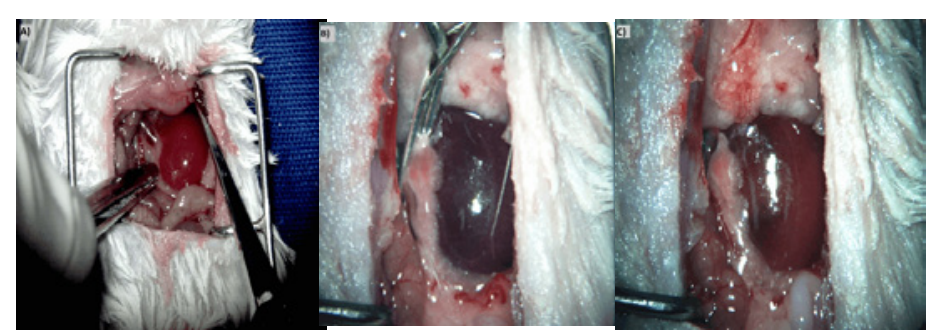

FIGURE 1 - Transitory renal ischemia resulting from the use of an aneurysm clip. A) Note the bright reddish color of the left kidney before clamping the renal hilum. B) After 40 minutes of renal ischemia, the kidney becomes dark. C) The re-perfusion is evident just after removing the clip.

\section{Induction of tumor ischemia in the allograft model}

Twenty BALBc mice bearing 4T1 allografts were subjected to surgery after seven days to induce tumor ischemia. Four animals were subjected to a surgical procedure where a suture knot was placed around the renal hilum, and the animals were sacrificed 24 hours after renal ischemia to analyze renal and tumor viability. The remaining animals were divided into the hypoxia group $(n=8)$, where the same protocol to create renal ischemia was performed as described above, and the control group $(n=8)$ was subjected to a sham surgery where the abdominal cavity was opened, the renal hilum identified, and then the abdominal wall was closed with a permanent suture 40 minutes later. Mice were sacrificed 7 or 14 days after the ischemic or sham procedures. The kidneys, lungs and liver were collected, weighed and fixed in $10 \%$ neutral formaldehyde. All tissues were processed in paraffin blocks.

\section{Histological assessment}

The kidneys and the lungs were cut longitudinally in half, and the livers were cut to a thickness of $5 \mathrm{~mm}$. All of the tissues were processed in paraffin blocks, and two $5 \mu \mathrm{m}$ slices from each block were mounted on one slide. The slides were stained with $H \& E$ and were analyzed via light microscopy. The presence of renal ischemic injury was confirmed by the histological identification of ATN characterized by degeneration of tubular architecture, loss of brush borders, sloughing tubular epithelial cells from the basement membrane, tubular cell necrosis and intratubular cast formation.

All slides of the lungs and livers were carefully analyzed, and the number of metastases was recorded. A high definition picture (100x) from each metastatic site was captured with an Olympus DP71 digital camera (Center Valley, PA, USA) built into the Olympus BX50 light microscope (Center Valley, PA, USA) using the software DP Controller version 2.3.1.231. The images were analyzed using the software Image J 1.46r (National Institute of Health, VA, USA) to estimate the area of each metastatic site. Figure 2 shows an example of how the metastatic lesion in the lung was measured.

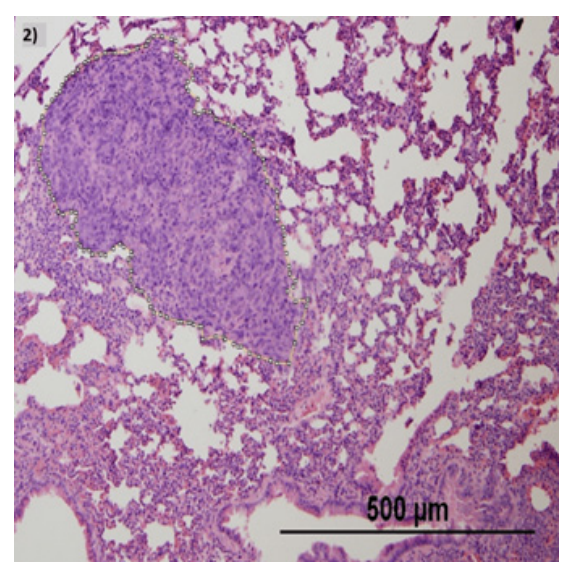

FIGURE 2 - 4T1 metastasis in the lung parenchyma. Quantification of the metastatic site was estimated using ImageJ software.

\section{Results}

\section{Tumor engraftment}

To study the feasibility of engrafting 4T1 cells into the renal parenchyma, we injected $5 \times 10^{4}$ or $10^{5}$ live $4 \mathrm{~T} 1$ cells into the renal cortex of BALBc mice. According to palpation of the abdomen, the presence of a tumor was evident in all of the mice after 10 days of engraftment. The histological evaluation confirmed that the injection of $5 \times 10^{4}$ or $10^{5} 4 \mathrm{~T} 1$ live cells into the renal cortex had a $100 \%$ engraftment success rate.

\section{Renal hypoxia}

To create hypoxia directed to the tumor site, we first confirmed that kidney hypoxia leads to a histological acute tubular necrosis (ATN). We analyzed the kidney histology of mice that were subjected to permanent or transitory renal hilum ligation. After 24 hours of renal hilum ligation with a permanent suture knot, histological ATN was evident in all of the mice. A transitory hypoxic state was induced for 40 minutes by clamping the renal hilum and was associated with a similar pattern in all of the mice. Figure $3 \mathrm{~A}$ and $\mathrm{B}$ show the renal cortex from a normal and an ischemic kidney, respectively. 


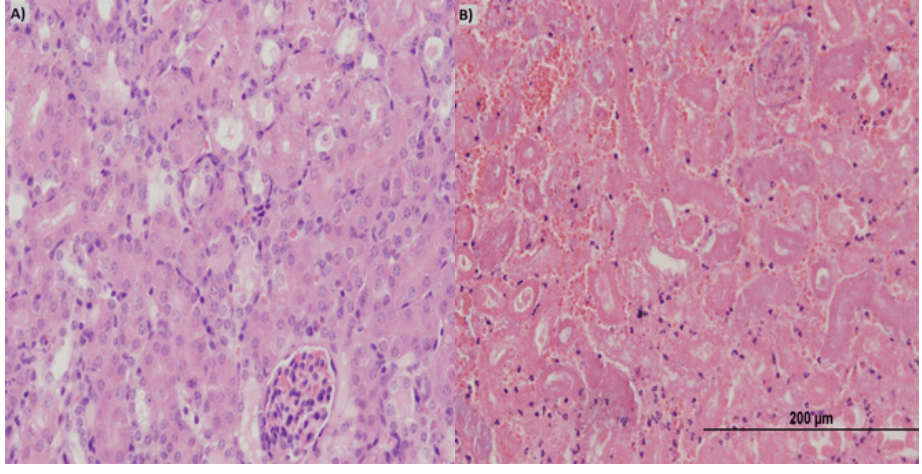

FIGURE 3 - Acute tubular necrosis (ATN) induced by permanent renal ischemia. A) Histology of a normal kidney in which the renal tubules and the glomerulus are observed. B) Histology of the renal cortex after renal ischemia. Note the degeneration of tubular architecture, loss of brush borders, sloughing tubular epithelial cells from the basement membrane, tubular cell necrosis and intratubular cast formation.

\section{Tumor hypoxia}

We analyzed the histology of four kidneys from mice bearing 4T1 allografts that were subjected to permanent renal and tumor ischemia for 24 hours. We observed that after this period, there was an evident and diffuse ATN. However, the tumor remained histologically intact demonstrating that cancer cells can tolerate a long period of hypoxia. Note that in Figure 4, intact tumor cells surround the renal cortex with a histological ATN. These first assays demonstrated that is possible to engraft tumor cells into the renal parenchyma it is possible to induce ischemia directed to the tumor site and confirm its efficacy using histological analysis.
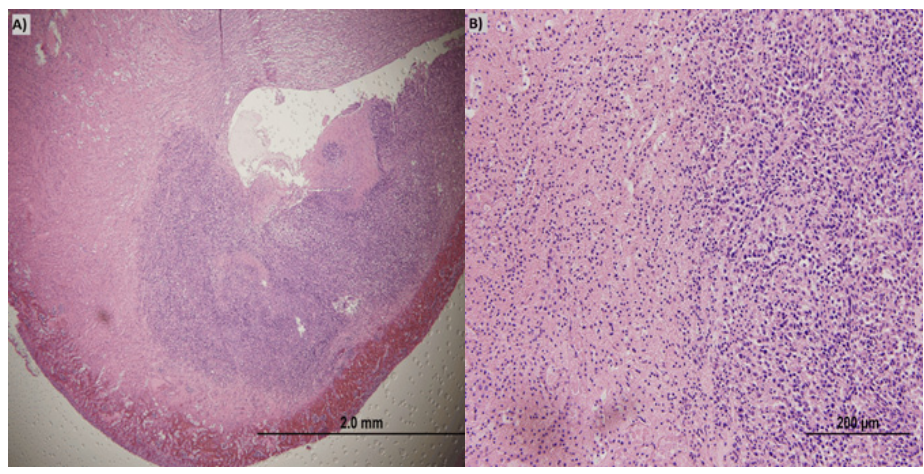

FIGURE 4 - The left kidney of a mouse was engrafted with 4T1 cells into the renal cortex, and after seven days a permanent ischemia was induced using a suture knot around the renal hilum. The slides show the renal cortex and the engrafted tumor after 24 hours of permanent ischemia. A) Note that the tumor is engrafted into the renal cortex (40x). B) The renal cortex displays evident ATN. However, most tumor cells are still histologically viable (200x).

We analyzed the macroscopic and microscopic pattern of tumor growth after seven and 14 days in two groups of mice bearing 4T1 allografts; one group was subjected to renal ischemia, and the other served as a control. The tumor was macroscopically evident in all mice. After 14 days of engraftment, only one animal presented with macroscopic tumor growth beyond the renal capsule in the control group $(n=4)$. In the hypoxia group, all of the tumors were evident beyond the renal capsule. The median kidney weight after 14 days of engraftment was $0.32 \pm 0.15 \mathrm{~g}$ and $0.45 \pm 0.07 \mathrm{~g}$ in the control and hypoxia groups, respectively. After 21 days of engraftment, all of the mice presented with tumor growth beyond the renal capsule. The mean kidney weight was $0.75 \pm 0.16 \mathrm{~g}$ and $0.89 \pm 0.37 \mathrm{~g}$ in the control and hypoxia groups, respectively. Figure $5 \mathrm{~A}$ and $\mathrm{B}$ show the kidneys engrafted with 4T1 cells in the control and hypoxia groups after seven and 14 days of engraftment, respectively.

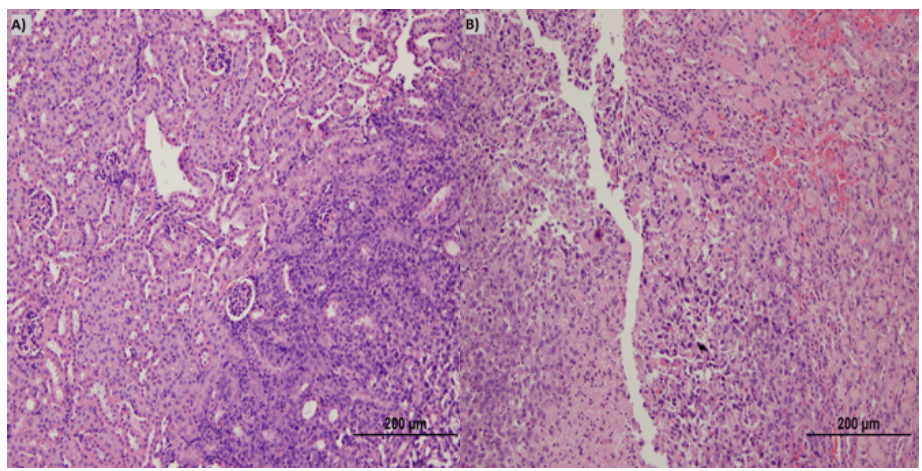

FIGURE 5 - Engraftment of 4T1 cells into the renal parenchyma of $\mathrm{BALBc}$ mice. A) In the control group, the tumor is growing into the normal renal cortex. B) In the hypoxia group, a viable tumor is growing into the renal cortex with evident ATN. An area of tumor necrosis is evident.

The engraftment of 4T1 cells into the kidney maintains the ability of the cells to metastasize. After 14 days of engraftment, we observed the presence of lung metastases in two out of three mice in the hypoxia group. No lung metastases were observed in the control group during this time period. After 21 days of engraftment, all of the mice presented with lung metastases in both groups. Mice did not develop liver metastases during the study follow-up. Table 1 quantifies the histological analysis of the lung metastases in both the control and hypoxia groups. 
TABLE 1 - Presence of lung metastases in a BALBc allograft model at 14 and 21 days after engraftment with $10^{5} 4 \mathrm{~T} 1$ cells into the renal cortex ( $\mathrm{C}$, control group; $\mathrm{H}$, hypoxia group). Tumor hypoxia was induced seven days after engraftment by clamping the renal hilum for 40 minutes.

\begin{tabular}{ccccc}
\hline & $\begin{array}{l}\text { C 14 } \\
\text { days }\end{array}$ & $\begin{array}{l}\text { H 14 } \\
\text { days }\end{array}$ & $\begin{array}{l}\text { C 21 } \\
\text { days }\end{array}$ & $\begin{array}{c}\text { H 21 } \\
\text { days }\end{array}$ \\
\hline $\begin{array}{l}\text { Presence of lung } \\
\text { metastases (n) }\end{array}$ & $0 / 4$ & $2 / 4$ & $4 / 4$ & $4 / 4$ \\
\hline $\begin{array}{l}\text { Number of } \\
\text { metastases }\end{array}$ & & & & \\
\hline Mouse 1 & 0 & 4 & 4 & 14 \\
Mouse 2 & 0 & 0 & 3 & 1 \\
Mouse 3 & 0 & 0 & 6 & 2 \\
Mouse 4 & 0 & 1 & 1 & 15 \\
\hline
\end{tabular}

Total area of lung

metastases $\left(\mathrm{mm}^{2}\right)$

\begin{tabular}{rcccc}
\hline Mouse 1 & 0 & 0.55 & 0.13 & 1.75 \\
Mouse 2 & 0 & 0 & 0.12 & 0.005 \\
Mouse 3 & 0 & 0 & 1.83 & 0.59 \\
Mouse 4 & 0 & 0.004 & 0.006 & 2.7 \\
\hline $\begin{array}{l}\text { Mean area of lung } \\
\left.\text { metastases (mm }{ }^{2}\right)\end{array}$ & 0 & $0.13 \pm 0.27$ & $0.52 \pm 0.87$ & $1.26 \pm 1.2$ \\
\hline
\end{tabular}

\section{Discussion}

Breast cancer is the leading cause of malignancy among women worldwide. Although novel therapeutic strategies have been developed during the past decades, the mechanisms and the reasons involved in why cancer cells metastasize are not well understood, and millions of women die every year due to breast cancer cell metastasis. The current predictive factors for cancer recurrence are based on the expression of tumor markers in a single tumor sampling. Considering that cancer progression is a multistep and dynamic event, developing models that enable the study of cancer progression and metastasis in vivo is essential. These models enable better understanding of how the microenvironment modulates or influences the tumor phenotypes, creating specific conditions for cancer cells to survive in an adverse setting and continue to harm the host.

We demonstrated here that is possible to induce hypoxia directed to the tumor site in an allograft mouse model without creating a complete state of tumor necrosis. Tumor hypoxia is one of the most important hostile factors that cancer cells have to undergo in order to create a tumor. The cellular response to tissue hypoxia triggers a cascade of phenomena that include the induction of the epithelial to mesenchymal transition, degradation of the basement membrane and extracellular matrix, increased cell motility, and tumor-stroma interactions that facilitate intravasation, extravasation and angiogenesis ${ }^{13}$. These biological processes are modulated by different pathways and promote tumor progression and dissemination ${ }^{14}$.

Many studies have reported that cancer cell adaptation to a hostile environment is responsible for clonal selection and expression of more aggressive phenotypes ${ }^{2-4}$. There are two 4T1 sibling cell lines with different metastatic properties (64NR and 168FARN). These lines were isolated from the same spontaneous arising BALB/c mammary tumor ${ }^{15,16}$, and inherit divergent pathways with distinct ability for acquisition of their metastatic phenotypes ${ }^{17}$. Significant gene expression profile has been reported between $4 \mathrm{~T} 1$ and $67 \mathrm{NR}$ cell lines. 4T1 cell line displays elevated levels of some genes known to be regulated by hypoxia and glucose deprivation (Gadd45, Pfkfb3, Vegfc, Flt1) suggesting that $4 \mathrm{~T} 1$ cells are in a stress-related state, with high metabolic requirements that are inadequately supplied by the vasculature ${ }^{18}$. Those observations open an opportunity to use the renal allograft model to study the influence of hypoxia over 67NR cell line.

Additionally, some modifications in this model can be performed to enhance the monitoring of tumor progression and dissemination. An alternative is to use the 4T1-luc2 cell line which was transfected with firefly luciferase gene (luc2). Thus, allograft tumors generated from 4T1-luc2 cells can be monitored using in vivo imaging systems ${ }^{19}$. The maintenance of metastatic ability allows the study of the influence of hypoxia in tumor dissemination. In fact, our preliminary results showed that mice underwent to tumor hypoxia are more likely to develop lung metastases. Another alternative is to develop xenograft models based on renal engraftment. We chose to use the allograft because the immune and inflammatory responses are closely linked to the tumor microenvironment modification ${ }^{18,20}$ and this allograft model permits to study the integration between tumor hypoxia and immune response.

\section{Conclusion}

This model can help us to understand how low oxygen tension mediates hypoxia-induced proteomic and genomic changes in breast cancer. 


\section{References}

1. Hockel M, Vaupel P. Tumor hypoxia: definitions and current clinical, biologic, and molecular aspects. J Natl Cancer Inst. 2001;93:266-76.

2. Bertout JA, Patel SA, Simon MC. The impact of $\mathrm{O}_{2}$ availability on human cancer. Nat Rev Cancer. 2008;8:967-75.

3. Semenza GL. Targeting HIF-1 for cancer therapy. Nat Rev Cancer. 2003;3:721-32.

4. Kaur B, Khwaja FW, Severson EA, Matheny SL, Brat DJ, Van Meir EG. Hypoxia and the hypoxia-inducible-factor pathway in glioma growth and angiogenesis. Neuro Oncol. 2005;7:134-53.

5. Schindl M, Schoppmann SF, Samonigg H, Hausmaninger H, Kwasny W, Gnant M, Jakesz R, Kubista E, Birner P, Oberhuber G. Over expression of hypoxia-inducible factor lalpha is associated with an unfavorable prognosis in lymph node-positive breast cancer. Clin Cancer Res. 2002;8:1831-7.

6. Kronblad A, Jirstrom K, Ryden L, Nordenskjold B, Landberg G. Hypoxia inducible factor-1alpha is a prognostic marker in premenopausal patients with intermediate to highly differentiated breast cancer but not a predictive marker for tamoxifen response. Int J Cancer. 2006;118:2609-16.

7. Yu L, Hales CA. Long-term exposure to hypoxia inhibits tumor progression of lung cancer in rats and mice. BMC Cancer. 2011;11:331

8. Terraneo L, Bianciardi P, Caretti A, Ronchi R, Samaja M. Chronic systemic hypoxia promotes $\mathrm{LNCaP}$ prostate cancer growth in vivo. Prostate. 2010;70:1243-54

9. Cairns RA, Hill RP. A fluorescent orthotopic model of metastatic cervical carcinoma. Clin Exp Metastasis. 2004;21:275-81.

10. Cairns RA, Hill RP. Acute hypoxia enhances spontaneous lymph node metastasis in an orthotopic murine model of human cervical carcinoma. Cancer Res. 2004;64:2054-61.

11. Kalliomaki TM, McCallum G, Lunt SJ, Wells PG, Hill RP. Analysis of the effects of exposure to acute hypoxia on oxidative lesions and tumour progression in a transgenic mouse breast cancer model. BMC Cancer. 2008;8:151.

12. Graves EE, Vilalta M, Cecic IK, Erler JT, Tran PT, Felsher D, Sayles L, Sweet-Cordero A, Le QT, Giaccia AJ. Hypoxia in models of lung cancer: implications for targeted therapeutics. Clin Cancer Res. 2010;16:4843-52

13. Harris AL. Hypoxia--a key regulatory factor in tumour growth. Nat Rev Cancer. 2002;2:38-47.

14. Semenza GL. Defining the role of hypoxia-inducible factor 1 in cancer biology and therapeutics. Oncogene. 2010;29:625-34.

15. Beasley NJ, Leek R, Alam M, Turley H, Cox GJ, Gatter K, Millard P, Fuggle S, Harris AL. Hypoxia-inducible factors HIF-1alpha and HIF-2alpha in head and neck cancer: relationship to tumor biology and treatment outcome in surgically resected patients. Cancer Res. 2002;62:2493-7.

16. Miller FR. Tumor subpopulation interactions in metastasis. Invasion Metastasis. 1983;3:234-42

17. Tao K, Li J, Warner J, MacLeod K, Miller FR, Sahagian GG. Multiple lysosomal trafficking phenotypes in metastatic mouse mammary tumor cell lines. Int J Oncol. 2001;19:1333-9.

18. Tao K, Fang M, Alroy J, Sahagian GG. Imagable 4T1 model for the study of late stage breast cancer. BMC Cancer. 2008;8:228.

19. Kim JB, Urban K, Cochran E, Lee S, Ang A, Rice B, Bata A, Campbell K, Coffee R, Gorodinsky A, Lu Z, Zhou H, Kishimoto TK, Lassota P. Non-invasive detection of a small number of bioluminescent cancer cells in vivo. PLoS One. 2010;5(2):e9364.

20. Kowanetz M, Wu X, Lee J, Tan M, Hagenbeek T, Qu X, Yu L, Ross J, Korsisaari N, Cao T, Bou-Reslan H, Kallop D, Weimer R, Ludlam MJ, Kaminker JS, Modrusan Z, van Bruggen N, Peale FV, Carano
R, Meng YG, Ferrara N. Granulocyte-colony stimulating factor promotes lung metastasis through mobilization of Ly6G+Ly6C+ granulocytes. Proc Natl Acad Sci U S A. 2010;107:21248-55.

\section{Correspondence:}

Daniel Guimarães Tiezzi

Departamento de Ginecologia e Obstetrícia

Hospital das Clínicas de Ribeirão Preto, USP

Avenida Bandeirantes, 3900

140480-900 Ribeirão Preto - SP Brasil

Tel.: (55 16)3602-2488

dtiezzi@usp.br

Received: September 24, 2012

Review: November 26, 2012

Accepted: December 20, 2012

Conflict of interest: none

Financial source: Fundação de Amparo ao Ensino, Pesquisa e Assistência (FAEPA) do HCFMRP/USP

${ }^{1}$ Research performed at Breast Disease Unit, Department of Gynecology and Obstetrics, Ribeirao Preto School of Medicine, University of Sao Paulo (USP). 